JHR

35,3

Received 11 September 2019 Revised 29 November 2019 4 February 2020

16 February 2020

Accepted 27 February 2020

\section{Waterpipe and cigarette tobacco smoking and depressive symptoms among public school students in central Jordan}

\author{
Sukaina Alzyoud \\ Department of Community and Mental Health, Faculty of Nursing, \\ Hashemite University, Zarqa, Jordan, and \\ Farah Massoud \\ Imperial College London School of Public Health, London, UK
}

\begin{abstract}
Purpose - Tobacco is the most widely used substance in the world that has been linked to several psychological problems. Few studies have assessed the relationship between dual (waterpipe and cigarette) tobacco smoking. This study aims to examine the relationship between dual tobacco use and symptoms of depression amongst its users.

Design/methodology/approach - A cross-sectional study using a random sample of school students was conducted to assess youth tobacco smoking in the central region of Jordan. A self-reported questionnaire including biographical information, smoking status and experience of depression symptoms was used with a sample of 9 th to 12 th-grade students. $\chi^{2}$ and regression test were used to analyze the data.

Findings - The final sample comprised 576 school students, of whom $60 \%$ were males. The age range was between 16 and 18 years (mean $=15.84$ years, $\mathrm{SD} \pm 0.97$ ). $30 \%$ of the participants were dual tobacco smokers. A significant difference was found between males and females, with males being more likely to be dual tobacco smokers compared to females. Two depressive symptoms ("feeling sad" and "having crying spells") had a significant likelihood amongst the youth who were dual smokers.

Originality/value - To the best of the authors' knowledge, this is the first study that aims to report the relationship between dual tobacco smoking and depressive symptoms. Prevention programs are crucial for raising awareness of the harmful effects of dual tobacco smoking and smoking cessation amongst the youth

Keywords Dual tobacco smoking, Depression, Waterpipe, Cigarettes, Jordan

Paper type Research paper
\end{abstract}

\section{Introduction}

According to the World Health Organization (WHO), smoking is considered to be one of the most pressing public health challenges. The number of tobacco smokers worldwide has reached 1.1 billion, accounting for $22.5 \%$ of the total population in 2019 , with a recorded $20 \%$ of that proportion being female and $80 \%$ being male [1,2]. Moreover, almost $17.6 \%$ of young people worldwide smoked tobacco products in 2015 [3]. Since the 1990s, an emerging and rapidly growing strain in the global tobacco epidemic has been a waterpipe ("hookah" or "shisha"), a centuries-old method of using tobacco with roots in the Middle East and Southeast Asia that has spread globally $[4,5]$. Waterpipe use has increased most dramatically

\footnotetext{
(C) Sukaina Alzyoud and Farah Massoud. Published in Journal of Health Research. Published by Emerald Publishing Limited. This article is published under the Creative Commons Attribution (CC BY 4.0) license. Anyone may reproduce, distribute, translate and create derivative works of this article (for both commercial and noncommercial purposes), subject to full attribution to the original publication and authors. The full terms of this license may be seen at http://creativecommons.org/licences/by/4.0/ legalcode

The author wishes to acknowledge the American University of Beirut Tobacco Control Research Group and the Syrian Center for Tobacco Studies.
}

Journal of Health Research Vol. 35 No. 3,2021 pp. $240-248$

Emerald Publishing Limited e-ISSN: 2586-940X

DOI 10.1108/JHR-09-2019-0209 
among the youth in no small part due to its widespread popularity as a social activity $[4,6]$. Among the youth in Middle Eastern and North African (MENA) countries, waterpipe use typically begins before the initiation of cigarette smoking and is currently more common than cigarette smoking $[4,7,8]$.

Dual tobacco use (i.e. concurrent use of waterpipes and cigarettes) is a growing problem in the MENA region [9]. Waterpipe smoking is closely associated with cigarette smoking and is a known gateway to cigarette smoking amongst the populations that have never smoked $[4,8$, $10,11]$. Furthermore, dual tobacco use is receiving attention from researchers as several findings have indicated its rise among waterpipe smokers $[7,12,13]$. It has been linked to age, sex, parental smoking and smoking in social gatherings [7, 12-14]. For some years now, tobacco smoking has been linked to depression, anxiety and other mental illnesses [15]. In recent years, considerable attention has been focused on depression and waterpipe smoking [16]. Berlin et al. [17] strongly reported that depression increases the risk of smoking and that smoking increases the risk of depression. Fluharty et al. [18] reported evidence for positive associations between tobacco smoking and developing depression afterward and vice versa. Their findings indicated that baseline depression was associated with some type of later smoking behavior, while other evidence confirmed that smoking exposure was associated with later depression. The majority of reported studies have assessed depression and cigarette smoking or waterpipe smoking exclusively [17-20]. However, to the best of the authors' knowledge, no previous studies have reported the relationship between dual tobacco smoking and depressive symptoms among the youth. Therefore, the current study aims to examine if a positive association between dual tobacco (cigarettes and waterpipes) use and the symptoms of depression exists.

\section{Methodology}

Study design

A cross-sectional descriptive survey design was used to assess dual tobacco smoking among youth waterpipe smokers for which a sample of Jordanian school students aged 16 to 18 years were recruited from a large central region of Jordan.

This study was conducted in one of the major governorates of Jordan, located east of Amman in the central part of Jordan. This governorate comprises 15\% (852,700) of the population of Jordan. The majority of residents are Jordanian Muslims and Christians. Additionally, previous work has indicated that school students in this governorate have high rates of waterpipe smoking [21]. It is also accessible to the study principal investigator, who has first-hand knowledge of the geographical area, expertise in the community culture and access to the school system.

\section{Population}

The study population included Jordanian students who attended public schools in the first educational district of the governorate during the academic year 2012-2013. Power analysis was conducted to determine the required sample size. Setting the significance level at $5 \%$ and power at $90 \%$ and estimating the prevalence of tobacco smoking among males and females as 27 and $35 \%$, respectively, the minimum sample size required to detect a difference between males and females was estimated to be a total of 1500 participants.

The participants were selected using cluster sampling, with schools as the randomization unit. In addition, three clusters were created for each sex: the first for schools serving 9th through 12th grades, the second for schools with 9th through 10th grades and schools with 11th through 12th grades and the third for schools with 9th grade and school with 10th through 12th grades. This method was used because schools have different set-ups in terms of grades. For instance, some only include 7-10th grades, others include grades from 1 to 12 and some have 11th and 12th grades only. Using simple random sampling, the researchers
Tobacco use and symptoms of depression 
JHR 35,3

\section{2}

randomly drew schools from each cluster for a total sample of 10 schools (one from the first cluster of females' schools, two from the females' second cluster, two from the females' third cluster, one from the male's first cluster, two from the males' second cluster and two from the males' third cluster). Finally, classrooms were randomly chosen for each selected school with all students in the selected classrooms eligible to participate in the study. The exclusion criterion was non-parental consent to participate in the study.

\section{Measures}

The participants were asked to take a self-administered survey that captured demographic information, such as age, grade, sex, weekly waterpipe use (number of waterpipes smoked in the past 7 days even if only one puff), if they smoked waterpipes alone, smoked cigarettes, religion and school academic performance (last year's grade point average (GPA)). An average GPA of $\geq 3.7$ was considered excellent, and an average GPA of $\leq 2$ was considered poor [22].

The dual smoking status of the participants was determined by using their positive selfreported responses about their cigarette and waterpipe smoking statuses. Dual tobacco smoking was measured by using a crosstab procedure to combine students' answers for the following two questions "Do you smoke waterpipes?" and "Do you smoke cigarettes". Participants who answered yes for both questions were considered as dual smokers. Another question indicating the use of tobacco other than waterpipe smoking when unavailable were also asked as follows "When I feel the need to smoke a waterpipe and it is unavailable, I smoke a cigarette instead." The symptoms of depression were measured by asking the participants if they experienced any of the following during the past seven days: "I felt lonely," "I had trouble keeping my mind on what I was doing," "I had crying spells," "I felt sad," "I felt that people disliked me," and "I could not get going." The response to these items used Likert-type items ranging between "Rarely or none of the time" to "Most or all of the time." These items were also part of a tobacco use questionnaire [21] that mainly consisted of multiple-choice questions with no reliability reported. Additionally, they are used as individual questions and not as one scale. These items are reflective of DSM-5 criteria [23] for depressive symptoms, including feelings of worthlessness, diminished interest or pleasure in activities, depressed mood most of the day and diminished ability to think or concentrate. The study measure was administered to the students in the Arabic language.

\section{Data collection}

After obtaining approval from the Institutional Review Board of Hashemite University (HU) number (7/9/2013/2014-21/09/2014) and the first educational district, the researchers sought verbal permission to conduct the study from the principal of each selected school. Ten schools (five girls and five boys) were visited for data collection. Two principals in the second cluster refused to allow the researchers' access to their students because of school exams; these schools were replaced by other schools from the same cluster.

All students in the selected classrooms were visited by trained research assistants (RAs), who then provided the students with a copy of the survey. The researchers instructed all the students in the classroom not to return the survey if they chose not to participate in the study. Prior to the completion of the survey, the researchers explained the study objectives and answered any questions from the participants. The participants also provided assent before beginning the questionnaire.

\section{Statistical analysis}

The statistical package for the social sciences (SPSS) was used to conduct data analysis. Data analysis began with preparatory activities such as the treatment of missing data and the identification of outliers, which were excluded from the final analysis. The chi-squared test was used to test the difference in dual tobacco smoking between male and female participants. 
Additionally, the test was used to explore the association between dual tobacco smoking and the use of cigarettes instead of waterpipes and the six items related to the symptoms of depression.

Simple logistic regression analysis (logistic procedures) was performed to measure the association of dual tobacco smoking as the outcome variable with age, sex, use of cigarettes instead of waterpipes and the six items related to the symptoms of depression. The significance for all analyses was set at $p \leq 0.05$.

\section{Results}

The final sample included in this study included only those who reported waterpipe smoking $(n=576)$ (Table 1$)$. The mean age was 16.2 years (SD \pm 0.83$)$. Moreover, $60 \%$ of those surveyed were males, and the proportion of males to females was 1.5:1. The vast majority $(98.1 \%)$ of the participants were Muslim Jordanians.

The mean reported number of waterpipes smoked per week was $3.35(\mathrm{SD}=3.71)$. The majority $(69.1 \%)$ of those surveyed reported smoking a waterpipe exclusively (by contrast, $30.9 \%$ said that they did not smoke waterpipes exclusively).

\section{Dual tobacco smoking}

The current study significantly reported the prevalence of dual tobacco smoking among school students. $30 \%(n=178)$ of the participants reported dual tobacco smoking (Table 1). The chi-squared test was used to test the difference in dual tobacco smoking between male and female participants. Table 2 shows the distribution of dual tobacco use according to sex. A significant difference is found between sex and dual tobacco smoking.

\section{Association between dual tobacco smoking and depressive symptoms}

Table 3 shows the distribution of the youth's experience of depressive symptoms and dual tobacco smoking. The chi-squared test was used to test the difference between dual tobacco smoking and the replacement of waterpipes with cigarettes when the former is unavailable. Moreover, the test was used to investigate the relationship between dual tobacco use and the six depressive symptoms items. The results indicated a significant relationship between dual smoking and the replacement of waterpipes with cigarettes when feeling lonely $(p: 0.006$ and $p$ : 0.001, respectively). Results showed a significant relationship between dual tobacco smoking and feeling sad ( $p$ : 0.03) but not with replacing waterpipe with a cigarette when the former was unavailable. On the other hand, a significant relationship was found between feeling disliked by others ( $p$ : 0.007$)$ and smoking cigarettes instead of waterpipes when the latter was unavailable.

The simple logistic model was performed to examine the relationship among the outcome variables, dual tobacco smoking, by sex, the replacement of a waterpipe with a cigarette when feeling the need to smoke and it is unavailable and six other items reflecting depressive symptoms (Table 4).

The likelihood for a male being a dual tobacco smoker is significantly higher than that of a female (OR: 0.378, 95\% CI: $0.21-0.68)$. Significantly, the youth are more likely to be dual smokers when they smoke cigarettes when waterpipes are unavailable (OR: 0.026, 95\% CI: $0.01-0.05)$. Two depressive symptoms, namely, feeling sad and having crying spells, were significantly associated with the youth who were dual smokers.

\section{Discussion}

The findings of the current study are consistent with previous research [7, 14, 24], if not slightly higher. Studies on youth and adults have demonstrated that waterpipe smokers are highly susceptible to become cigarette smokers [10,25]. This age group was chosen due to recent studies indicating that waterpipe usage is surging among Jordanian youth [21, 26, 27].
Tobacco use and symptoms of depression 
JHR

35,3

244

Variable

Sex

Male

Female

Grade

9th Grade

10th Grade

11th Grade

12th Grade

Religion

Muslim

Christian

Nationality

Jordanian

Non-jordanian

551

19

Previous year's GPA

Excellent (90-100\%)

Very good $(80-89 \%)$

Good (70-79\%)

Fair $(60-69 \%)$

Poor $59 \%$ or less

Do you smoke a waterpipe alone?

Yes

No

Have you ever felt like you really needed to smoke a waterpipe?

Yes

286

No

290

How frequently do you usually smoke waterpipes per week?

Never

Once

Twice

3-6 times a week

7 times or more a week

When I feel the need to smoke a waterpipe and it is unavailable, I smoke a cigarette instead

Yes

125

451

35

206

100

136

99

No

$\begin{array}{rr}38 & 6.6\end{array}$

Dual tobacco (cigarettes and waterpipes) smoking

$\begin{array}{ll}\text { Dual smoker } & 178 \\ \text { Waterpipe only smoker } & 398\end{array}$

Note(s): The total values may not add up to the exact $\%$ due to missing values

Table 2.

Distribution of dual tobacco use according to $\operatorname{sex}(n=576)$

\begin{tabular}{lllcc}
\hline & & & Dual tobacco smoking $(n=178)$ & $p$-Value* \\
\hline \multirow{2}{*}{ Sex } & Males & Yes & $136(23.6 \%)$ & 0.000 \\
& & No & $210(36.5 \%)$ & \\
& Females & Yes & $42(7.3 \%)$ & \\
& No & $188(32.6 \%)$ &
\end{tabular}


Furthermore, late adolescence is typically a time of experimentation [28], and the youth aged between 19 and 24 represent almost 20\% of the Jordanian population [29]. The current findings are congruent with previous findings [27] of the same population, dual tobacco smoking was also evident, and this continuation of the problem indicates that further examination of this phenomenon and its contributing factors amongst this age group is needed.

Study findings indicated that the youth would smoke cigarettes when they felt the need to smoke waterpipes but the latter was unavailable. To the best of the authors' knowledge, this is the first study to report such a significant finding. Over the years, researchers have demonstrated that waterpipe smoking is as addictive as cigarette smoking [26, 30, 31]. This scenario could contribute to the high prevalence of waterpipe smoking $(21.7 \%$ in the current study), where smokers are faced with the need for readily available nicotine sources to satisfy their nicotine cravings. It could also be contributed to the feelings of cravings, which subsequently tempt the youth to replace waterpipes with cigarettes.

Study findings indicated that males were more likely to be dual tobacco smokers compared to females. This finding confirms previous results among the same population of a high prevalence of dual tobacco use among males [32,33]. In a study among school students in the north of Jordan, McKelvey et al. [12] concluded that dual cigarette/waterpipe smoking was significantly higher in males than females. A reason for this result could be attributed to

\begin{tabular}{|c|c|c|c|c|}
\hline & \multicolumn{2}{|c|}{ Dual tobacco smoking } & \multicolumn{2}{|c|}{$\begin{array}{c}\text { When I feel the need to } \\
\text { smoke a waterpipe } \\
\text { and it is unavailable, } \\
\text { I smoke a cigarette } \\
\text { instead }\end{array}$} \\
\hline & $X$-square & $p$-Value & $X$-square & $p$-Value \\
\hline I had trouble keeping my mind on what I was doing & 3.92 & 0.27 & 0.44 & 0.93 \\
\hline I felt lonely & 14.5 & $0.006^{*}$ & 20.2 & $0.001^{*}$ \\
\hline I had crying spells & 2.3 & 0.5 & 4.2 & 0.23 \\
\hline I felt sad & 8.4 & $0.03^{*}$ & 3.6 & 0.3 \\
\hline I felt that people disliked me & 7.6 & 0.05 & 11.9 & $0.007 *$ \\
\hline I could not get "going" & 6.9 & 0.41 & 3.6 & 0.45 \\
\hline
\end{tabular}

Note(s): $* p<0.05$
Tobacco use and symptoms of depression

Table 3.

Association of the youth's experience of depressive symptoms and dual tobacco smoking

\begin{tabular}{lcc}
\hline Variable & $\mathrm{OR} \dagger$ & $95 \%$ C.I. \\
\hline Sex & & \\
Female & & Ref \\
Male & 0.378 & $0.21-0.68^{*}$ \\
When I feel the need to smoke waterpipe and it is not available, I smoke & a cigarette instead & \\
Nos & & Ref \\
Yes & 0.026 & $0.01-0.05^{*}$ \\
I had trouble keeping my mind on what I was doing & 0.872 & $0.66-1.14$ \\
I felt lonely & 0.865 & $0.64-1.15$ \\
I had crying spells & 1.382 & $1.03-1.85^{*}$ \\
I felt sad & 0.76 & $0.58-0.99^{*}$ \\
I felt that people disliked me & 1.2 & $0.91-1.57$ \\
I could not get "going" & 0.79 & $0.61-1.04$
\end{tabular}

Table 4.

Association of dual tobacco smoking and depressive symptoms

Note(s): $† \mathrm{OR}=$ odds ratio; $\mathrm{CI}=$ confidence interval; $* p<0.05$ 
JHR

35,3

the sample lifestyle in urban areas where cafes and family's social interactions are highly accommodating of youth tobacco smoking. Another reason could be that the parents of our sample youth are also cigarette smokers and/or dual smokers. Veeranki et al. [7] found that the youth's exposure to parental dual-use is associated with a significant increase in waterpipe smoking only and dual-use.

A thorough search of the existing literature shows that this is the first study to report the association between dual smoking and depressive symptoms. A significant association was found between the feelings of sadness and loneliness with dual smoking. Moreover, regression results indicated a significant likelihood between dual smoking and feeling sad. This result is consistent with that of previous studies [18, 30,34, 35] in terms of smoking and depressive symptoms; however, this study showed novel findings linking dual smoking to depression. Supporting this result is the significant association between replacing waterpipes with cigarettes when feeling lonely and needing to smoke the former, which could be contributed to the youth's urge to satisfy their cravings for a smoke. This confirms the reports of youth experiencing depressive symptoms as a result of smoking cessation [18]. It was demonstrated that waterpipe smoking delivers nicotine efficiently to the smoker [36] and that waterpipe smoking is associated with classical signs of tobacco/nicotine dependence, such as craving and withdrawal [37]. Therefore, the youth might resolve to replace a waterpipe with a cigarette to overcome the signs of withdrawal when the former is not available. Another factor could be the youth's attempt to ease such symptoms by replacing waterpipes with cigarettes when the former is unavailable. A study among the youth indicated that smoking progression predicted the delay of depression symptoms from mid to late adolescence [38]. These findings are significant in supporting previous studies and providing explicit evidence for the reported susceptibility of waterpipe smokers to become cigarette smokers $[8,25]$. Further research is crucial to understanding the relationship between dual smoking and depressive symptoms. Additionally, prevention programs for addressing the harmful effects of dual smoking are essential among the youth. Prevention programs and efforts should focus on the effect of nicotine dependence and how the youth might replace one action (in this case smoking a cigarette) when trying to deal with depressive symptoms.

However, the current study has some limitations. The main limitation includes the use of self-report measures that relied on the recall and memory of the participants. Another limitation is that the data only includes one governorate, which may limit generalizing our results to the rest of the country. However, our multistage cluster random sample and the characteristics of our sample can be reflective of all the youth from the same age group.

\section{Conclusion}

The current study reported the relationship between dual tobacco smoking and depressive symptoms. It also significantly corroborated that the youth replace waterpipes with cigarettes when waterpipes are unavailable, but they experienced feelings of sadness

combined with the need to smoke. Prevention is crucial to raising the awareness of the harmful effects of tobacco smoking and smoking cessation among the youth.

\section{References}

1. World Health Organization [WHO]. Tobacco. 2019. Available from: https://www.who.int/newsroom/fact-sheets/detail/tobacco.

2. World Health Organization [WHO]. 10 facts on gender and tobacco 2010. Available from: https:// www.who.int/gender/documents/10facts_gender_tobacco_en.pdf.

3. Gowing LR, Ali RL, Allsop S, Marsden J, Turf EE, West R, Witton J. Global statistics on addictive behaviours: 2014 status report. Addiction. 2015; 110(6): 904-19. 
4. Maziak W, Taleb ZB, Bahelah R, Islam F, Jaber R, Auf R, Salloum RG. The global epidemiology of waterpipe smoking. Tob Control. 2015; 24(Suppl 1): i3-i12.

5. Rastam S, Ward KD, Eissenberg T, Maziak W. Estimating the beginning of the waterpipe epidemic in Syria. BMC Publ. Health. 2004; 4: 32.

6. De Leon E, Smith KC, Cohen JE. Dependence measures for non-cigarette tobacco products within the context of the global epidemic: a systematic review. Tob Control. 2014; 23(3): 197-203.

7. Veeranki SP, John RM, Ibrahim A, Pillendla D, Thrasher JF, Owusu D, Ouma AEO, Mamudu HM Age of smoking initiation among adolescents in Africa. Int J Public Health. 2017; 62(1): 63-72.

Tobacco use and symptoms of depression

8. Jaber R, Madhivanan P, Veledar E, Khader Y, Mzayek F, Maziak W. Waterpipe a gateway to cigarette smoking initiation among adolescents in Irbid, Jordan: a longitudinal study. Int J Tuberc Lung Dis. 2015; 19(4): 481-7.

9. Mostafa A, El Houssinie M, Fotouh AA. Multiple tobacco use among young adult waterpipe smokers in Egypt. East Mediterr Health J. 2018; 24(1): 7-17.

10. Kheirallah KA, Alzyoud S, Ward KD. Waterpipe use and cognitive susceptibility to cigarette smoking among never-cigarette smoking Jordanian youth: analysis of the 2009 Global Youth Tobacco Survey. Nicotine Tob Res. 2015; 17(3): 280-4.

11. Veeranki SP, Alzyoud S, Kheirallah KA, Pbert L. Waterpipe use and susceptibility to cigarette smoking among never-smoking youth. Am J Prev Med. 2015; 49(4): 502-11.

12. McKelvey K, Attonito J, Madhivanan P, Jaber R, Yi Q, Mzayek F, Maziak W. Determinants of waterpipe smoking initiation among school children in Irbid, Jordan: a 4-year longitudinal analysis. Drug Alcohol Depend. 2014; 142: 307-13.

13. Jawad M, Lee JT, Millett C. The relationship between waterpipe and cigarette smoking in low and middle income countries: cross-sectional analysis of the global adult tobacco survey. PLoS One. 2014; 9(3): e93097.

14. Hessami Z, Masjedi MR, Mortaz E, Heydari G, Kazempour-Dizaji M, Sharifi H, Jamaati H. Evaluation of dual tobacco smoking (water pipe and cigarettes) and associated factors in adults in tehran. Tanaffos. 2016; 15(3): 180-6.

15. Fergusson DM, Goodwin RD, Horwood LJ. Major depression and cigarette smoking: results of a 21-year longitudinal study. Psychol Med. 2003; 33(8): 1357-67.

16. Sabahy AR, Divsalar K, Bahreinifar S, Marzban M, Nakhaee N. Waterpipe tobacco use among Iranian university students: correlates and perceived reasons for use. Int J Tuberc Lung Dis. 2011; 15(6): 844-7.

17. Berlin I, Covey LS, Glassman AH. Smoking and depression: a co-morbidity. J Dual Diagn. 2009: 5(2): $149-58$.

18. Fluharty M, Taylor AE, Grabski M, Munafo MR. The association of cigarette smoking with depression and anxiety: a systematic review. Nicotine Tob Res. 2017; 19(1): 3-13.

19. Martini S, Wagner FA, Anthony JC. The association of tobacco smoking and depression in adolescence: evidence from the United States. Subst. Use Misuse. 2002; 37(14): 1853-67.

20. Weinberger AH, Kashan RS, Shpigel DM, Esan H, Taha F, Lee CJ, Funk AP, Goodwin RD. Depression and cigarette smoking behavior: a critical review of population-based studies. Am J Drug Alcohol Abuse. 2017; 43(4): 416-31.

21. Alzyoud S, Weglicki LS, Kheirallah KA, Haddad L, Alhawamdeh KA. Waterpipe smoking among middle and high school Jordanian students: patterns and predictors. Int J Environ Res Public Health. 2013; 10(12): 7068-82.

22. Crimson Education. How to calculate your GPA?; 2017. Available from: https://www. crimsoneducation.org/au/blog/average-gpa-ivy-league.

23. Association AP. American Psychiatric Association Diagnostic and statistical manual of mental disorders. 5th ed. Washington, DC: American Psychiatric Association; 2013. 
JHR

35,3
24. Kheirallah KA, Alsulaiman JW, Mohammad HA, Alzyoud S, Veeranki SP, Ward KD. Waterpipe tobacco smoking among arab youth; a cross-country study. Ethn Dis. 2016; 26(1): 107-12.

25. Salloum RG, Haider MR, Barnett TE, Guo Y, Getz KR, Thrasher JF. Waterpipe tobacco smoking and susceptibility to cigarette smoking among young adults in the United States, 2012-2013. Prev Chronic Dis. 2016; 13: E24.

26. Alzyoud S, Veeranki SP, Kheirallah KA, Shotar AM, Pbert L. Validation of the waterpipe tolerance questionnaire among Jordanian school-going adolescent waterpipe users. Glob J Health Sci. 2015; 8(2): 198-208.

27. Alzyoud S, Kheirallah KA, Weglicki LS, Ward KD, Al-Khawaldeh A, Shotar A. Tobacco smoking status and perception of health among a sample of Jordanian students. Int J Environ Res Public Health. 2014; 11(7): 7022-35.

28. Viner RM, Ross D, Hardy R, Kuh D, Power C, Johnson A, Wellings K, McCambridge J, Cole TJ, Kelly Y, Batty GD. Life course epidemiology: recognising the importance of adolescence. J Epidemiol Community Health. 2015; 69(8): 719-20.

29. United Nations Development Programme. Jordan human development report 2015. Available from: https://www.jo.undp.org/content/dam/jordan/docs/Publications/NDHR/Jordan $\% 20 \mathrm{Human} \%$ 20Development $\% 20$ Finalest.pdf.

30. Maziak W. The global epidemic of waterpipe smoking. Addict Behav. 2011; 36(1-2): 1-5.

31. McKelvey K, Attonito J, Madhivanan P, Yi Q, Mzayek F, Maziak W. Determinants of cigarette smoking initiation in Jordanian schoolchildren: longitudinal analysis. Nicotine Tob Res. 2015; 17(5): 552-8.

32. Ali M, Gray TR, Martinez DJ, Curry LE, Horn KA. Risk profiles of youth single, dual, and poly tobacco users. Nicotine Tob Res. 2016; 18(7): 1614-21.

33. Soneji S, Sargent J, Tanski S. Multiple tobacco product use among US adolescents and young adults. Tob Control. 2016; 25(2): 174-80.

34. Dos Santos VA, Migott AM, Bau CH, Chatkin JM. Tobacco smoking and depression: results of a cross-sectional study. Br J Psychiatry. 2010; 197(5): 413-4.

35. Kang E, Lee J. A longitudinal study on the causal association between smoking and depression. J Prev Med Public Health. 2010; 43(3): 193-204.

36. Maziak W, Rastam S, Shihadeh AL, Bazzi A, Ibrahim I, Zaatari GS, Ward KD, Eissenberg T. Nicotine exposure in daily waterpipe smokers and its relation to puff topography. Addict. Behav. 2011; 36(4): 397-9.

37. Maziak W, Rastam S, Ibrahim I, Ward KD, Shihadeh A, Eissenberg T. CO exposure, puff topography, and subjective effects in waterpipe tobacco smokers. Nicotine Tob Res. 2009; 11(7): 806-11.

38. Audrain-McGovern J, Rodriguez D, Kassel JD. Adolescent smoking and depression: evidence for self-medication and peer smoking mediation. Addiction. 2009; 104(10): 1743-56.

\section{Corresponding author}

Sukaina Alzyoud can be contacted at: sukainaalzyoud@gmail.com

For instructions on how to order reprints of this article, please visit our website:

www.emeraldgrouppublishing.com/licensing/reprints.htm

Or contact us for further details: permissions@emeraldinsight.com 